mediastudies.press • Social Media \& the Self: An Open Reader

\title{
Understanding Facebook's Algorithm Could Change How You See Yourself
}

\section{Alexis Papazoglou}

Published on: Aug 17, 2019

License: Creative Commons Attribution-NonCommercial 4.0 International License (CC-BYNC 4.0). 
WHEN WE GO online these days, we know we're not alone: The internet is looking back at us. Our clicks give us the information and products we ask for, but at the same time they provide information about us. Algorithms then make use of that data to curate our search results, our social media feeds, and the advertisements we see. The internet ascribes an identity to its users, and projects it back to us.

The research behind the political campaigns run by Cambridge Analytica in 2016 suggested that a few Facebook likes are enough for an algorithm to identify our gender, personality traits, sexual orientation, religious and political beliefs. "Computerbased personality judgments," two psychologists and a computer scientist claimed in a research paper in 2015, can "be more accurate than those made by humans." The algorithms can end up knowing us better than our spouses do. If that's true-not all researchers think it is-what does that mean for our own understanding of who we are? ...

\section{continue reading}

\section{OUTBOUND LINK}

"Understanding_Facebook's Algorithm Could Change How You See Yourself"

(Alexis Papazoglou, The New Republic, April 17, 2019)

METERED PAYWALL (3 free articles per month) 